MATEC Web of Conferences 13,02009 (2014)

DOI: $10.1051 /$ matecconf/ 20141302009

(C) Owned by the authors, published by EDP Sciences, 2014

\title{
Cycle-by-cycle Variations in a Direct Injection Hydrogen Enriched Compressed Natural Gas Engine Employing EGR at Relative Air-Fuel Ratios.
}

\author{
Wasiu Saheed Olalekan ${ }^{1, a}$, A.A. Rashid ${ }^{1}$, Masri Baharom ${ }^{1}$ \\ ${ }^{1}$ Department of Mechanical Engineering, Universiti Teknologi Petronas, Malaysia
}

\begin{abstract}
Since the pressure development in a combustion chamber is uniquely related to the combustion process, substantial variations in the combustion process on a cycle-by-cycle basis are occurring. To this end, an experimental study of cycle-by-cycle variation in a direct injection spark ignition engine fueled with natural gashydrogen blends combined with exhaust gas recirculation at relative air-fuel ratios was conducted. The impacts of relative air-fuel ratios (i.e. $\lambda=1.0,1.2,1.3$ and 1.4 which represent stoichiometric, moderately lean, lean and very lean mixtures respectively), hydrogen fractions and EGR rates were studied. The results showed that increasing the relative air-fuel ratio increases the COVIMEP. The behavior is more pronounced at the larger relative air-fuel ratios. More so, for a specified EGR rate; increasing the hydrogen fractions decreases the maximum $\mathrm{COV}_{\text {IMEP }}$ value just as increasing in EGR rates increases the maximum COV IMEP value. (i.e. When percentage EGR rates is

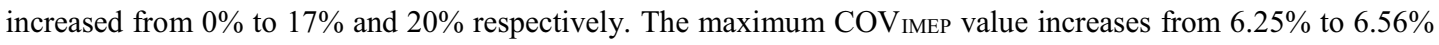
and $8.30 \%$ respectively). Since the introduction of hydrogen gas reduces the cycle-by-cycle combustion variation in engine cylinder; thus it can be concluded that addition of hydrogen into direct injection compressed natural gas engine employing EGR at various relative air-fuel ratios is a viable approach to obtain an improved combustion quality which correspond to lower coefficient of variation in imep, (COV IMEP $)$ in a direct injection compressed natural gas engine employing EGR at relative air-fuel ratios.
\end{abstract}

Keywords-Coefficient of variation in indicated mean effective pressure ( $\left.\mathrm{COV}_{\mathrm{IMEP}}\right)$; Direct injection compressed natural gas (DI-CNG); Exhaust gas recirculation (EGR); Hydrogen fractions; Relative air-fuel ratios.

\section{Introduction}

An effective approach to overcome these challenge of slow burning velocity and poor lean burn capability of natural gas fuel is to mix natural gas with the fuel that possess fast burning velocity. Hydrogen is regarded as the best gaseous candidate for natural gas due to its very fast burning velocity; much better lean capability and small quenching distance. This combination is expected to improve the lean-burn characteristics and reduces the engine emission. Unfortunately, this method always increases the combustion temperature and heat loss to the cylinder wall as well as high $\mathrm{NO}_{\mathrm{X}}$ emission [3-5]. Thus some approaches like ultra-lean combustion or EGR need to be adopted combining with hydrogen addition to realize low $\mathrm{NO}_{\mathrm{X}}$ emission in a natural gas-hydrogen fuelled engine [6].

Cycle by cycle combustion variation exists in spark ignition engine and this phenomenon will become more severe at lean mixture condition. Previous studies were conducted on the cycle-by-cycle variations of the spark ignition engines. The results generally revealed that variations in the early combustion stage mainly determined the cycle-by-cycle variation of the engines [5-7]. The strategy

\footnotetext{
${ }^{a}$ Corresponding author : engineerlk2003@yahoo.com
} 
which can increase the burning velocity of the mixtures will lead to the reduction of the cycle-bycycle variations of the engine. Till date, no literature has ever examined the cycle-by-cycle variations in a hydrogen enriched compressed natural gas engine employing EGR at various relative air-fuel ratios. Thus, the objective of this study is to investigate the effects of different fractions of hydrogen gas on the cycle-by-cycle variation of the direct injection compressed natural gas (DI-CNG) engine employing EGR at various relative air-fuel ratios.

\section{Experimental Set up}

The specifications of the test engine are listed in Table 1 below. A four-stroke single cylinder research engine was used to investigate the effect of hydrogen gas on a cycle-by-cycle variation of the directinjection compressed natural gas engine employing EGR at relative air-fuel ratios and under partthrottled condition. Figure 1 below shows the schematic diagram of the experimental set up.

TABLE 1: Engine Specifications And TeSt Bed

\begin{tabular}{|l|l|}
\hline \multicolumn{2}{|c|}{ Engine Properties } \\
\hline Displacement volume & $399.25 \mathrm{~cm} 3$ \\
\hline Cylinder Bore & $76 \mathrm{~mm}$ \\
\hline Cylinder Stroke & $88 \mathrm{~mm}$ \\
\hline Compression Ratio & 14 \\
\hline Exhaust Valve Closed & ATDC $10^{\circ}$ \\
\hline Exhaust Valve Open & BBDC $45^{\circ}$ \\
\hline Inlet Valve Open & BTDC $12^{\circ}$ \\
\hline Inlet Valve Closed & ABDC $48^{\circ}$ \\
\hline Dynamometer & Eddy Current with maximum reading of 50Nm \\
\hline ECU & Orbital Inc \\
\hline
\end{tabular}

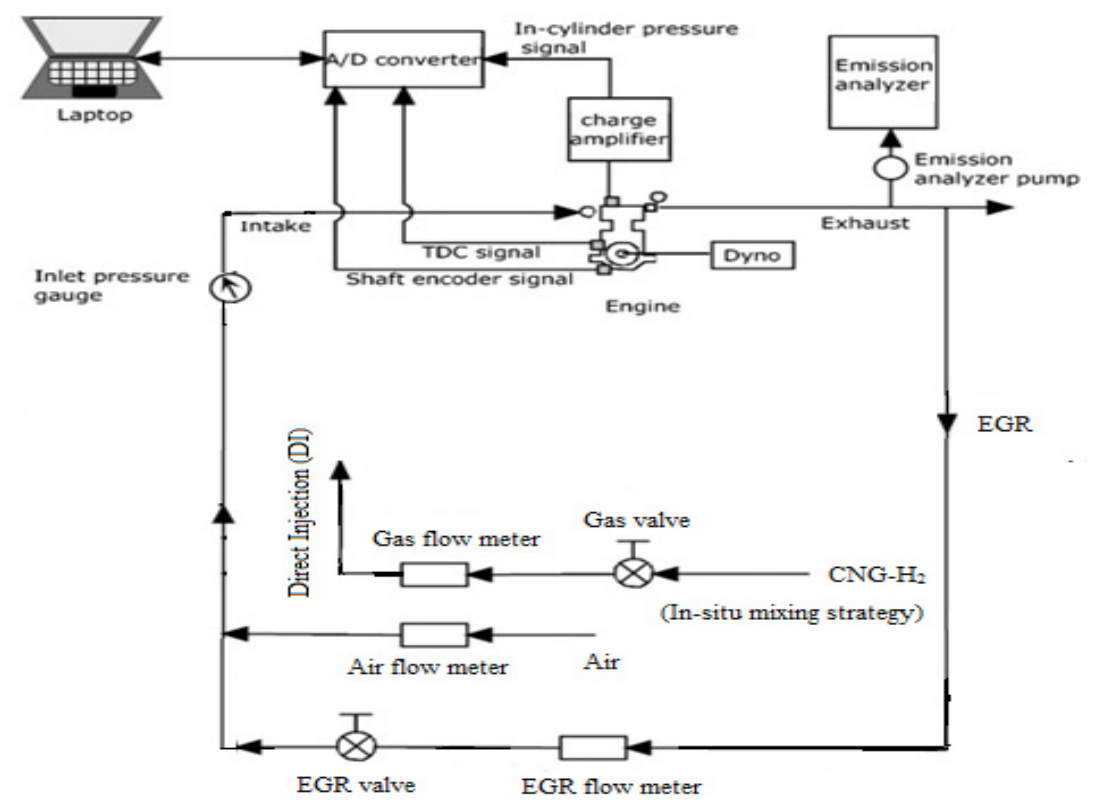

Figure 1. Schematic illustration of experimental setup 
The supplying system of the engine consists of a natural gas-hydrogen blend (mixed together using in- situ strategy), gas valve, gas flow meter, a pressure regulator. An electronic control unit was used to adjust the amount of $\mathrm{CNG}-\mathrm{H}_{2}$ gas and the excess air ratio into the system, also controlled by the electronic system was also injection timing. Experiments was conducted after running the engine until it reached steady state, with oil temperature at $60^{\circ} \mathrm{C}$ and cooling water temperature $70^{\circ} \mathrm{C}$. The experimental work was started by directly injecting a mixture of $\mathrm{CNG}-\mathrm{H}_{2}$ into the engine cylinder while simultaneously recycling the exhaust gas from a hole located on the exhaust pipe with the aid of connecting pipe. A regulating valve was installed in order to regulate the exhaust gas flow. Percentage increase of EGR in the inlet mixture was done by increasing the amount of the exhaust gas flowing back to the engine intake system. Air and exhaust gas were mixed in the engine intake, while $\mathrm{CNG}-\mathrm{H}_{2}$ was directly injected into the engine. A $5 \mathrm{~mm}$ square orifice meter was used to measure the flow rate of the exhaust gases recycled back into the engine intake. The pressure difference across the orifice meter was measured using $U$ tube manometer. The percentage of the exhaust gases recycled back to the engine intake was calculated as a percentage of the total inlet mass flow rate as follows:

$$
\% E G R=\frac{m_{E G R}}{m_{I N T A K E}} \times 100
$$

The equation for determining the mass flow rate of EGR is given below:

$$
m_{E G R}=C A_{2} \sqrt{2 \rho \Delta \mathrm{P}}
$$

Where:

$$
\begin{aligned}
& m_{E G R} \quad=\text { mass flow rate of EGR }(\mathrm{kg} / \mathrm{s}) \\
& A_{2}=\text { Area of the orifice plate }\left(\mathrm{m}^{2}\right) \\
& \rho \quad=\text { Density of the combustible products }\left(\mathrm{kg} / \mathrm{m}^{3}\right) \\
& \Delta \mathrm{P}=\text { Pressure difference from the orifice plate }\left(\mathrm{N} / \mathrm{m}^{2}\right) \\
& C \quad=\text { Coefficient of flow } \\
& m_{\text {INTAKE }}=\text { Total mass flow rate of intake }(\mathrm{kg} / \mathrm{s})
\end{aligned}
$$

A pressure gauge was used to measure the inlet pressure. Fig. 2.0 below shows the schematic diagram of the EGR control system.

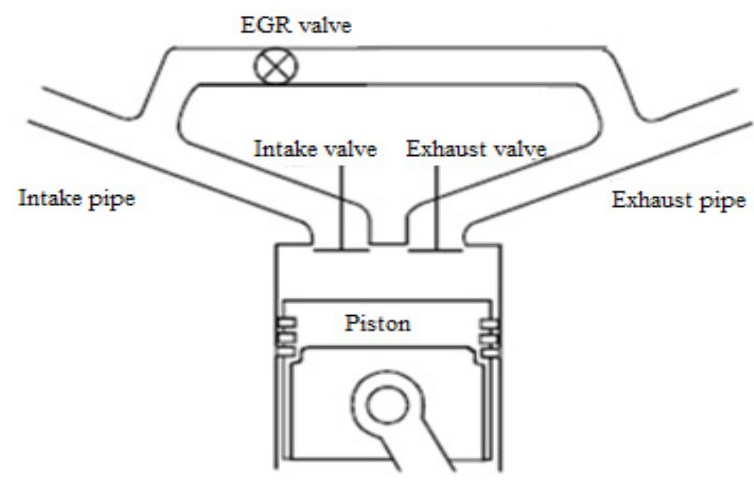

Figure 2. Schematic diagram of the EGR control system 
The research was carried out at part-throttled, with spark timing set at $26.0^{\circ} \mathrm{CA}$, injection timing of $300^{\circ} \mathrm{CA}$ (which represent early injection timing), and four (4) relative air-fuel ratios $(\lambda=1.0,1.2,1.3$ and 1.4) which represent, stoichiometric, moderately lean; lean and leaner mixtures respectively and constant engine speed of $2000 \mathrm{r} / \mathrm{mins}$, were being utilized.

\section{Results and Discussions}

Figure 3.0 below shows the relationship of coefficient of variation in indicated mean effective pressure $\left(\mathrm{COV}_{\text {IMEP }}\right)$ against relative air-fuel ratios for different percentage by volume of hydrogen gas at various EGR rates.

$\mathrm{COV}_{\text {IMEP }}$ - is one important measure of cyclic variability, derived from pressure data. It is the standard deviation in IMEP divided by the mean IMEP and it is usually expressed in percent (\%). Mathematically, it is given as:

$$
C O V_{I M E P}=\frac{\sigma_{I M E P}}{I M E P_{\text {avg }}}
$$

Where:

$$
\sigma_{\text {IMEP }}(\mathrm{kPa}) \text { is the standard deviation in indicated mean effective pressure. }
$$

$I M E P_{a v g}(\mathrm{kPa})$ is the average indicated mean effective pressure calculated for a number of a cycle.

$\mathrm{COV}_{\text {IMEP }}$ is a measure of the cyclic variability in indicated work per cycle. It is an important parameter to determine the stable operating limit of the engine. Empirically, it has been found that vehicle driveability problem usually results when $\mathrm{COV}_{\text {IMEP }}$ exceeds $10 \%$.

Figure 3.0 (a) - (c) shows that increasing the excess air ratio increase the $\mathrm{COV}_{\text {IMEP. }}$ The behavior is more pronounced at the larger excessive air ratios (i.e. $\lambda=1.2-1.4$ ).

More so, for a specified EGR rate; increasing the hydrogen fraction decreases the COV $\mathrm{IMEP}_{\text {as }}$ it can be seen in figure 3.0 (a) - (c) where the largest cycle-by-cycle (i.e. highest COV) occurs at $0 \% \mathrm{H}_{2}$ as compared to $28 \% \mathrm{H}_{2}$ and $46 \% \mathrm{H}_{2}$ respectively with $46 \% \mathrm{H}_{2}$ having the lowest $\mathrm{COV}_{\text {IMEP. }}$

However, the large cycle-by-cycle variation that occurs at $0 \% \mathrm{H}_{2}$ (i.e natural gas ) are due to slow burning velocity at lean mixture combustion; while introduction of hydrogen into natural gas can increase the burning velocity and decrease the misfire or partial burning cycle; which ultimately lead to decrease in cycle-by-cycle combustion variation occasioned by addition of hydrogen fraction. From the foregoing; it is technically reasonable to say that addition of hydrogen into natural gas is a viable approach to improve engine stability at lean mixture operation.

Moreover, consider the effect of increasing EGR rates on the maximum $\mathrm{COV}_{\text {IMEP }}$ for all the figures under $\mathrm{COV}_{\text {IMEP }}$ i.e. Figure 3.0 (a) - (c); It clearly shows that increasing the percentage EGR rate increases the maximum $\mathrm{COV}_{\text {IMEP }}$ value as it can be seen when percentage EGR rate is increased from $0 \%$ to $17 \%$ and $20 \%$ respectively. The maximum $\operatorname{COV}_{\text {IMEP }}$ value increases from $6.25 \%$ to $6.56 \%$ and $8.3 \%$ respectively. The increase in $\mathrm{COV}_{\text {IMEP }}$ as a result of increasing EGR rates occurs because increasing the EGR rate causes an increase in cycle-by-cycle combustion variation due to variation in mixture composition or gas motion in the engine cylinder. 


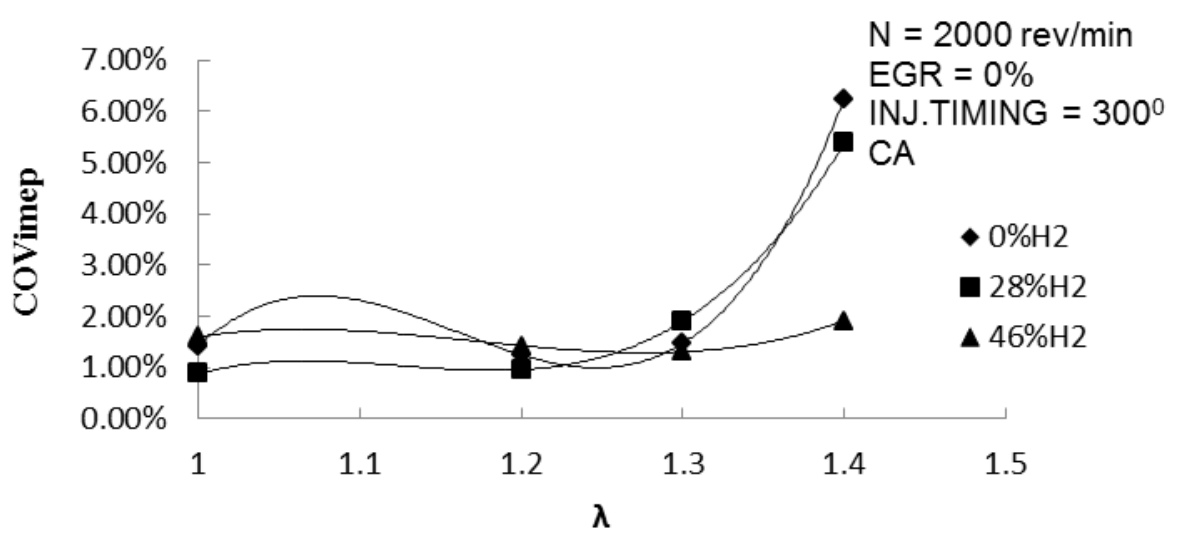

(a)

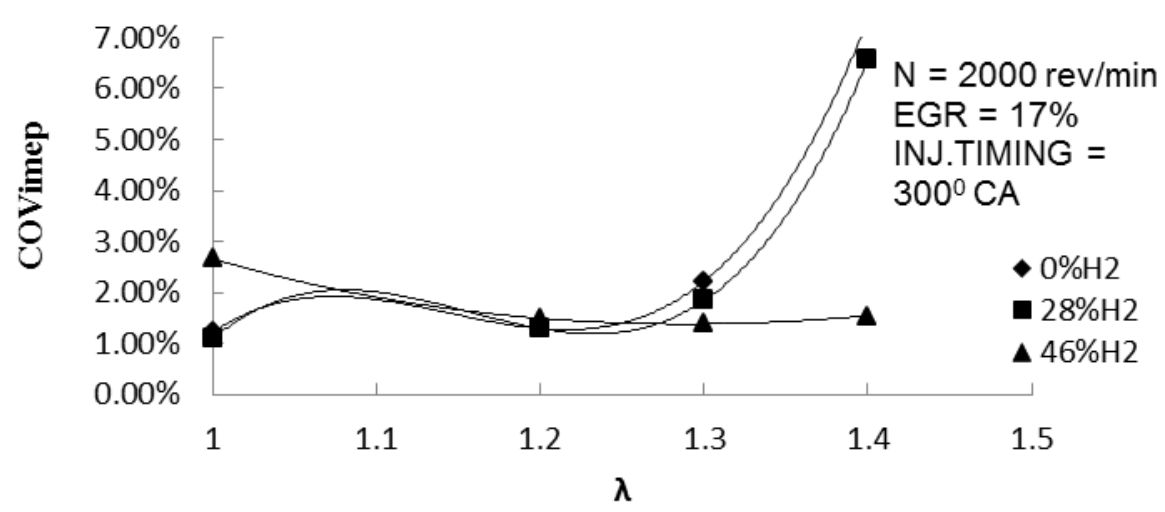

(b)

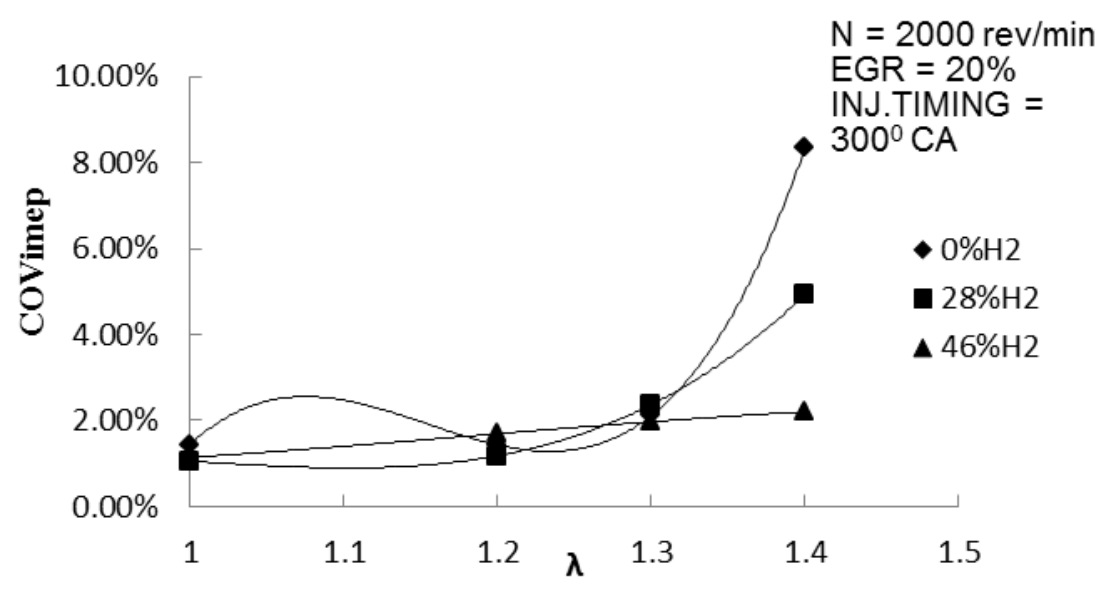

(c)

Figure 3. Relationship of coefficient of variation in indicated mean effective pressure ( $\left.\mathrm{COV}_{\mathrm{IMEP}}\right)$ against relative air-fuel ratios for different percentage by volume of hydrogen gas at various EGR rates 


\section{Conclusion}

An experimental study on the effects of different fractions of hydrogen gas on cycle-by-cycle combustion variations of the direct injection compressed natural gas engine employing EGR at relative air-fuel ratios ( $\lambda=1.0,1.2,1.3$ and 1.4 which represent stoichiometric; moderately lean, lean and leaner mixtures respectively) under part-throttled condition was conducted. The main results are summarized as follows:

1. $\operatorname{COV}_{\text {IMEP }}$ increases with increasing in relative air-fuel ratios $(\lambda=1.0,1.1,1.2,1.3$, and 1.4). This effect is more pronounced at larger relative air-fuel ratios (i.e. $\lambda=1.2-1.4$ ).

2. $\mathrm{COV}_{\mathrm{IMEP}}$ decreases as the hydrogen fraction increases while it increases with increase of EGR rates.

3. From the foregoing; it is technically reasonable to say that addition of hydrogen into natural gas engine employing EGR rates at various relative air-fuel ratios is a viable approach to improve the combustion quality (i.e. lower $\mathrm{COV}_{\mathrm{IMEP}}$ ).

\section{Acknowledgement}

Financial support of Universiti Teknologi PETRONAS is highly acknowledged.

\section{References}

[1] S. Rousseau, B. Lemoult, M. Tazerout,. J of Automobile Eng 213, 481-9 (1999)

[2] L. Ben, NR. Dacro, R. Truquet, G. Charnay, SAE paper no.992901 (1999)

[3] S. Akansu, Z. Dulger, N. Kahraman, T. Veziroglu, Int J of Hydrogen Energy 14, 1527-39 (2004)

[4] A. Das, HC. Watson, J of Automobile Eng, 211, 361-78 (1997)

[5] J. Heywood, Internal Combustion Engine 130-140,371-390 (1988).

[6] F. Ma, Y. Wang, H. Liu, Y. Li, J. Wang, S. Ding.. Int J Hydrogen Energy 33, 823-31 (2008)

[7] H. Bin., H. Erjiang, H. Zuohua, Z. Jianjun, B. Liu., D. Jiang.. Int J Hydrogen energy 19, 8405-8414 (2009). 